\title{
ELEMENTOS PARA UNA PEDAGOGÍA DE LA ALTERIDAD EN LA PRÁCTICA DE EDUCADORAS SOCIALES. UN ESTUDIO NARRATIVO
}

\author{
Elements for a pedagogy of the otherness in social \\ educadors' practice. A narrative inquiry
}

\section{Éléments pour une pédagogie de l'altérité dans la pratique des éducateurs sociaux. Une étude narrative}

\author{
Clara ARBIOL GONZÁLEZ \\ Universitàt de València. Facultat de Filosofia i Ciències de l'Educació. Departament \\ de Didàctica i Organització Escolar. Blasco Ibáñez, 30. 46010 València. \\ clara.arbiol@uv.es
}

Fecha de recepción: enero de 2018

Fecha de aceptación: marzo de 2018

\section{RESUMEN}

El texto es fruto de una investigación narrativa que explora la práctica de cuatro educadoras sociales para indagar en el saber que las sostiene en la creación de relaciones educativas, un saber que proviene de la experiencia y que tiene su origen en la relación. El presente artículo se centra en mostrar la exploración de la experiencia de las educadoras sociales para señalar lo que podrían constituir elementos para una pedagogía de la alteridad en su práctica de relación educativa. Para ello, presento brevemente los ejes que guían la investigación, así como el proceder de la misma -una indagación narrativa-, para centrarme en los hallazgos: elementos del saber de la experiencia de las educadoras como elementos para una pedagogía de la alteridad. Es en esta parte donde pongo a dialogar la experiencia de las educadoras con la literatura en relación a la alteridad y la pedagogía del otro. 
Palabras clave: alteridad; narrativa; experiencia pedagógica; educación social; saber pedagógico; investigación educativa.

\section{SUMMARY}

The text is the result of a narrative investigation that explores the practice of four social educators to investigate the knowledge that sustains them in the creation of educational relationships, a knowledge that comes from experience and that has its origin in the relationship. This article focuses on showing the exploration of the experience of social educators to indicate what could constitute elements for a pedagogy of alterity in their practice of educational relationship. For this, I present briefly the axes that guide the investigation as well as the procedure of the same -a narrative inquiry-, to focus on the findings: elements of the knowledge of the experience of educators as elements for a pedagogy of alterity. It is in this part where I put to dialogue the experience of the educators with the literature in relation to the alterity and the pedagogy of the other.

Key words: otherness; narrative; pedagogical experience; social education; pedagogical knowledge; educational research.

\section{SOMMAIRE}

Le texte est le résultat d'une enquête narrative qui explore la pratique de quatre éducateurs sociaux pour étudier les connaissances qui les soutiennent dans la création de relations éducatives, une connaissance qui provient de l'expérience et qui a son origine dans la relation. Cet article s'attache à montrer l'exploration de l'expérience des éducateurs sociaux pour indiquer ce qui pourrait constituer des éléments pour une pédagogie de l'altérité dans leur pratique de la relation éducative. Pour cela, je présente brièvement les axes qui guident l'enquête ainsi que la procédure de la même enquête narrative, pour mettre l'accent sur les résultats: éléments de la connaissance de l'expérience des éducateurs en tant qu'éléments d'une pédagogie de l'altérité. C'est dans cette partie que j'ai mis en dialogue l'expérience des éducateurs avec la littérature par rapport à l'altérité et à la pédagogie de l'autre.

Mots clés: altérité; récit; expérience pédagogique; éducation sociale; connaissances pédagogiques; recherche en éducation.

\section{INTRODUCCIÓN}

Una idea algo altisonante, pero inquietante a la vez: la alteridad no es tanto lo que no somos, sino tal vez todo aquello que aún no hemos sido capaces de ser (Skliar, 2009, 155). 
La relación educativa es una relación de encuentro con otros y otras, la educación solo es posible si el otro está ahí. El presente texto es fruto de una investigación narrativa en que estudio la práctica de cuatro educadoras sociales para indagar en el saber que las sostiene en la creación de relaciones que sean, efectivamente, relaciones educativas. Las educadoras van conformando su práctica en relación a aquello que aprenden en una experiencia de exposición de relación, por una parte, con lo otro, que es fundamentalmente aquello que tiene que ver con el componente institucional de la práctica educativa en el contexto de la acción social; por otra parte, de la relación con una misma, en un trabajo de autoexploración y mesura que deben ir construyendo; y, finalmente, en un trabajo de relación con las otras y con los otros. Me pregunto aquí por esta relación con otras y otros, por el saber que nace del encuentro como un saber que nos conforma, un saber que viniendo del otro y del encuentro con el otro y la otra tiene un efecto subjetivador en nosotras como educadoras. Por cómo este saber nos dispone a eso que aún no hemos sido capaces de ser, y nos proporciona elementos para una pedagogía de la alteridad.

\section{LOS EJES DE LA INVESTIGACIÓN: RELACIÓN, EXPERIENCIA Y SABER}

Las claves que sostienen esta investigación -la relación educativa, la experiencia y el saber de la experiencia- se han ido construyendo en un proceso en que la búsqueda epistemológica va de la mano de la exploración metodológica.

\subsection{La relación educativa}

La relación educativa es la relación central en la práctica educativa, sin embargo, explicarla resulta de una enorme dificultad. Dice María-Milagros Rivera que "Educar es algo que se hace en relación y es fruto, a su vez, de la relación" (2012, 36). Pero cuando no nombramos la relación, la damos por supuesta y tomamos un atajo para escapar de la inmensa complejidad que entraña. "Es en la relación donde todo ocurre y me ocurre» (Arnaus, 2005, 38), no hay educación sin práctica de relación, en ella reside la posibilidad de una práctica educativa fructífera. Preguntarse por la relación es preguntarse por lo que la hace posible, por lo que la sostiene. "Supone partir de un cierto extrañamiento, de una cierta distancia», dice Núria Pérez de Lara $(2009$, 49), la relación es el misterio del encuentro con el otro, siempre imprevisible. Así, esta investigación no pretende resolver sino explorar, sin desvelar el misterio que entraña la relación educativa: cómo se (re) crea en la relación de cada educadora con otras y otros, con qué invenciones -la práctica es allá donde se encuentran experiencia, invención y consciencia (Rivera, 2011)-, qué de su experiencia de relación queda como saber, cómo las educadoras sociales acompañan, crean y sostienen relaciones educativas con otros, con ellas mismas, con lo otro. 


\subsection{La experiencia}

Decir algo sobre la experiencia, como hacerlo sobre la alteridad, puede llegar a ser lo mismo que intentar conservar un puñado de agua: a la vez que la sentimos, que durante un momento hemos pensado que lo hemos conseguido, sin embargo, al sacar la mano del agua, solo vemos cómo chorrea, como se nos escapa. Y, sin embargo, la hemos sentido, hemos podido percibir las sensaciones que nos produce [...] (José Contreras, 2009, 7).

Explorar la noción de experiencia es difícil, por lo que tiene de escurridiza, de inapresable, por eso en esta indagación lo que puedo es señalar algunas notas de lo que implica explorar la experiencia. En primer lugar, explorar la experiencia es explorar la experiencia de la encarnación. La experiencia siempre es de alguien, es en un cuerpo, en un cuerpo sexuado, es lo que me pasa, no lo que pasa (Larrosa, 2003); remite siempre a un sujeto que padece y sostiene la experiencia; experiencia y subjetividad son inseparables (Contreras y Pérez de Lara, 2010, 25); toda experiencia es experiencia de la propia historicidad (Gadamer, 1977, 434); la experiencia siempre será la experiencia de la singularidad (Larrosa, 2009, 29). En segundo lugar, explorar la experiencia es explorar la experiencia del pasaje, un tránsito: en la experiencia, cuando es de verdad, hay transformación, la del viaje que supone salir de sí mismo "hacia el otro, o hacia sí mismo como otro, ante otro, frente a otro» (Mèlich, 2002, 79). La experiencia es un pasaje formativo a través del cual conformamos nuestra subjetividad (Contreras y Pérez de Lara, 2010). Que una vivencia sea significativa y que podamos hacer el pasaje de la experiencia reside no en lo que pasa sino en la capacidad de verlo, de percibirlo (Faccincani, 2002); hace falta una cierta apertura de la mirada: la experiencia es atención, escucha, disponibilidad, sensibilidad, vulnerabilidad y exposición (Larrosa, 2009).

En tercer lugar, explorar la experiencia es explorar (con) la mediación de la palabra. La transmisión de la experiencia necesita de la narración tal como decía Benjamin (1998), hacer experiencia es, en gran medida, experimentar los límites del lenguaje: "Es parte de la experiencia misma el buscar y encontrar las palabras que la expresen» (Gadamer, 1977, 501). Se trata de un ejercicio de tensión entre experiencia y sentido (Clandinin y Connelly, 2000), la búsqueda de un lenguaje que sea fiel, un movimiento de «invención en el lenguaje»(Zamboni, 2002, 25).

Finalmente, explorar la experiencia es explorar una relación con el espacio y con el tiempo. Jean Clandinin y Michael Connelly (2000), Clandinin (2006 y 2013) hablan de tres dimensiones que atraviesan la narrativa, tienen que ver con los tres aspectos que John Dewey identifica en la experiencia: la interacción -toda experiencia es personal, pero tiene efectos en lo social-, la dimensión situacional -en la experiencia se cruzan diferentes escenarios- y la continuidad -en la experiencia se encuentran los tiempos pasado, presente y futuro-. La experiencia es reflexivi$\mathrm{dad}$, un pensar y pensarse, siempre implica un recordar, "la necesidad de la mirada retrospectiva. [...] un ver que es entrever» (Zambrano, 2011, 123). 


\subsection{El saber (de la experiencia)}

La experiencia puede ser origen. Preguntarnos por el saber de las educadoras significa preguntarnos por un saber que es fruto de la experiencia y que, a la vez, puede ser origen de nueva experiencia, que nos deja entrever algo, que nos conforma, que nos transforma. Exploro la experiencia de las educadoras para descubrir el saber que sostiene su práctica, que tiene sentido en la misma experiencia, que no es fácilmente traducible en conocimientos adquiridos, un saber incorporado, singular. En la investigación he intentado acompañar la emergencia de este saber, consciente de que este trabajo -el círculo existente entre práctica y experiencia (Piussi, 2007, 84) - era pasaje fundante de un hacer educativo más sabio que permite poner en el mundo prácticas educativas; comunicable; que no resuelve la pregunta, sino que muestra la necesidad de formularla cada vez; un saber que se puede ver desequilibrado por cualquier situación nueva (Cifalli, 2005), y que para emerger necesita de la mediación de la palabra. La manera en que me he podido acercar a esta experiencia es la indagación narrativa tal y como lo explico a continuación.

\section{UN CAMINO A RECORRER, UN CAMINO POR HACER. LA METODOLOGÍA DE INVESTIGACIÓN}

Dice María Zambrano (2011) que el método es un camino, un camino a recorrer una y otra vez, que no está definido, que debe crearse. Así, la metodología que acompaña esta investigación se piensa justo desde ese lugar; una manera de recorrer el camino que lo cree, que lo acompañe, que pueda sostener las preguntas de investigación; si el sentido de la investigación era explorar la experiencia, la metodología de indagación tiene que ser respetuosa con la complejidad que la experiencia entraña: "Why we use narrative inquiry? Because narrative inquiry is a way, the best way we believe, to think about experience» (Clandinin y Connelly, 2000, 80). La indagación narrativa me permite acercarme a la experiencia de las educadoras en tanto que relato.

\subsection{La indagación narrativa como forma de pensar (y explorar) la experiencia}

Si la investigación educativa quiere acompañar el movimiento de lo educativo en su propia naturaleza delicada, tiene que ser también delicada y frágil, hacerse más sensible y perceptiva a las cuestiones existenciales de la educación, abrirse a ser, en sí misma, una experiencia. La indagación narrativa me permitía acercarme a la experiencia de las educadoras sin perder lo que hace que esta sea tal, sin convertirla en otra cosa. La indagación narrativa es a la vez metodología y fenómeno a estudiar; estudia la vida vivida en tanto que relato; piensa narrativamente la experiencia; va siguiendo el saber -encarnado, situado, singular- de la experiencia. En las historias que las educadoras cuentan de sí y de su práctica se muestra la complejidad de la práctica educativa, el juego entre la inmanencia y la trascendencia 
que siempre atraviesa el hacer, un saber que cobra sentido en la acción (Tardif, 2004) y que se muestra sostenido en un relato.

La indagación narrativa es una manera de estudiar las vidas humanas que reconoce la experiencia vivida como origen de conocimiento, saber y comprensión (Clandinin, 2013); explora cómo la experiencia individual tiene lugar en relación con experiencias institucionales, lingüísticas, sociales, culturales, familiares; atendiendo a las vidas narradas de las personas que participan, estudiándolas a través de la escucha, de la observación, del acompañamiento, de la escritura. La indagación narrativa supone ante todo una experiencia relacional, a través de la cual las investigadoras y las participantes van transformándose en un ciclo de vivir-contarrevivir-recontar (Clandinin y Connelly, 2000).

En tanto que experiencia relacional, el proceder indagador que da forma a la investigación necesita recrearse en cada relación singular, hay que inventar el método (Van Manen, 2003), un camino «que no ofrece a su vez preparación ni guía alguna: lugar de llegada más que de partida” (Zambrano, 2011), que responde a la lógica de la creación más que a la de la aplicación. "Los caminos, (métodos) no pueden venir determinados por unos indicadores fijos: tienen que ser descubiertos o inventados como respuesta a la pregunta en cuestión” (Van Manen, 2003, 47).

A partir del trabajo de Clandinin (2013) identificamos las diferentes fases del diseño de una indagación narrativa: en primer lugar, una primera fase de composición de la pregunta de investigación, una pregunta que lejos de establecerse de una manera definitiva se va recomponiendo en el encuentro con las participantes. A esta composición Clandinin la llama Research Puzzles (42). En segundo lugar, lo que llama being in the midst (43), que designa una manera determinada de estar en lo real en que acompañamos desde la implicación a las participantes living alongside). En tercer lugar, el tránsito que hacemos del "campo" a los textos de campo. El término campo es la manera de designar el espacio que se abre entre la investigadora y las participantes, un espacio que hay que negociar, construir y crear en relación. Los textos de campo son la manera de designar lo que emerge como evidencia, como dato, como piezas que la investigadora recoge y que pueden ser imágenes, registros, transcripciones de conversaciones, anotaciones de diario de investigación... Con estos textos podemos elaborar los textos provisionales -interim texts (47) - que son textos provisionales fruto de la co-composición, estos textos se pueden compartir con las participantes o con otras investigadoras para hacerlos crecer y convertirlos en los textos de investigación.

En la investigación han participado cuatro educadoras sociales que han trabajado en experiencias, proyectos y entidades diversas, con mujeres, adolescentes y menores. Con ellas se ha mantenido la relación investigadora durante tres años. Cuatro, únicamente, porque la indagación requiere la observación pausada y continuada y la búsqueda de espacios distendidos y tiempos largos para favorecer el diálogo. Al diseñar el proceso de investigación se ponderó más el número de entrevistas que el número de informantes. En un primer momento se contactó con más educadoras, lo que permitió establecer criterios para elegir con quién 
continuar el proceso: en este enfoque metodológico se prima la significatividad y no la representatividad a la hora de seleccionar a las participantes, así se seleccionó a cuatro educadoras que mostraban disposición a pensar la propia práctica, que tenían recorrido de reflexión sobre la experiencia, que permitían abordar diferentes elementos en el estudio de la relación educativa por la vinculación con diferentes ámbitos de trabajo y, finalmente, educadoras con las que fue posible establecer una relación de confianza porque quien está invitada a hablar desde sí debe encontrar un espacio de reconocimiento, tener la certeza de que su palabra será acogida, respetada, escuchada.

\subsection{Las prácticas de investigación}

En el proceso de esta investigación he encontrado dos maneras de ponerme en relación con las educadoras y con su experiencia: la conversación hermenéutica (Van Manen, 2003) y el relato. Son prácticas de investigación en tanto que representan creaciones singulares, situadas, fruto de la atención a lo que (nos) pasa en la investigación.

\subsubsection{La conversación}

La conversación tiene un impulso hermenéutico (Gadamer, 1977; Van Manen, 2003), un movimiento de investigación, de búsqueda. La conversación es el espacio de la relación y el espacio de la experiencia. No se puede conversar sin apertura, es un circular la palabra, ir emergiendo el sentido, ir buscando de nuevo la pregunta; en la conversación nos exponemos, nos ponemos en relación desde nosotras, la conversación es un espacio para experimentar la relación con otra, su encuentro. La verdadera conversación, dice Gadamer (1977), no se lleva, se trata, más bien, de entrar en la conversación; lo que nazca de la conversación es algo imprevisible, es precisamente la apertura lo que posibilita el diálogo, "para que los hilos de la conversación puedan ir tejiéndose, es necesaria la apertura a lo otro» (1992, 204), lo que no quiere decir fundirse con el otro, ocupar su lugar (1977). Requiere experimentar al otro como otro, una experiencia de alteridad en la que contener la tentación de la categorización de la otra y de su experiencia. La apertura significa acoger lo otro como nuevo a lo que he de hacer espacio en mí, no reduciéndolo a lo que ya sé: para que haya escucha, es necesario que el mundo no esté acabado (Irigaray, 1994). Por ello, en la conversación no resulta fácil medir la tentación de la participación inmediata (Gadamer, 1977).

La otra con quien investigas ha de confiar, nos ha de autorizar, la investigación de la experiencia requiere la creación de un vínculo fundado en el reconocimiento para que fructifique. El conversar, dice Maturana (1997), se funda en el amor, como aceptación del otro o la otra, que nos hace poder entrar en conversación. Las conversaciones con las educadoras se extendieron a lo largo de dos años y entre ellas 
ha ido mediando el trabajo de relación, hemos ido construyendo la relación. Para que la palabra del otro pueda fructificar, sin desplazarla a nuestro horizonte conceptual (Mortari, 2002), hay que generar una disposición al encuentro sustrayéndose a la instrumentalización de la palabra. Procuré que las tres conversaciones con cada educadora, y las cuatro conversaciones grupales en las que han participado tres educadoras cada vez, fueran un espacio de sosiego, de cuidado.

Jorge Larrosa (2006) apunta la posibilidad de una lengua que sea nuestra, con sujeto, que no sea una lengua poseída, sino una lengua que esté entre nosotras, que no es discurso, ni metáfora que sustituye la realidad por palabras, sino una lengua que sea capaz de, con el lenguaje, tocar algo de lo real que anida en las experiencias singulares de quienes se encuentran en la conversación, fiel a su complejidad, su dificultad y su imprevisibilidad. En las primeras conversaciones me costó encontrar una forma de comenzar que invitara a la otra a hablar desde su experiencia; encontré una fórmula semejante a la que Luigina Mortari (2002) utilizó con Elisabetta Manenti y cuenta en su relato, un pedir a la otra que cuente aquello que para ella es significativo de lo que hace, para ir tejiendo las siguientes, tomando como partida aquello que emergía de los encuentros e ir entresacando los hilos que me permitieron crear los relatos.

\subsubsection{Los relatos de experiencia}

La experiencia tiene una forma narrativa (Contreras y Pérez de Lara, 2010; Clandinin y Connelly, 2000; Van Manen, 2003). A través del relato, la experiencia se muestra. En las conversaciones con las educadoras, esta cualidad narrativa de la experiencia era evidente: iban tejiendo un relato a partir de su ser educadora, de su pensarse, de lo que habían ido viviendo. El lenguaje de la experiencia, apuntaba Benjamin (1998), es el lenguaje de la narración. Somos contadoras de historias (Connelly y Clandinin, 1995). La experiencia se muestra a través del lenguaje y para poder ser contada a otras necesita del relato: mantenernos fieles a la experiencia no proviene de la repetición de los hechos en palabras, sino de la búsqueda de significado que la experiencia necesita para ser. Por ello, la escritura de la experiencia no es simplemente una forma de representar aquello vivido, no se trata de traducirlo en palabras. Es un movimiento más complejo, un intento constante de encontrar el sentido. La escritura es una búsqueda (Conle, 2000), no la representación de algo que está cerrado, sino un proceso creativo de ir construyéndolo (Conle, 1999). La escritura de la experiencia es aquella que reconstruye, junto a las prácticas y los acontecimientos, la trama que la compone como vivencia, busca su hilo conductor, indaga en sus cualidades pedagógicas (Contreras y Orozco, 2016).

En la indagación de la experiencia, la escritura es el método de exploración, porque a través de la escritura la experiencia se va significando, la escritura muestra nuestra capacidad reflexiva (Van Manen, 2003). La escritura necesita de distancia, pero esta distancia no rompe, solo interrumpe para fructificar, nos coloca en el terreno del pensamiento que se distancia de la práctica, pero que nace de ella y nos 
devuelve a ella, más perceptivas, más atentas. Dice Van Manen que escribir ejercita la capacidad de ver y, a la vez, los límites y las fronteras de aquello que podemos ver. La escritura deviene una experiencia de tensión entre la posibilidad que se abre y la imposibilidad que nos mantiene en la experiencia. Y eso que vemos hay que mostrarlo a través del relato.

Una escritura, entonces, que deja ver, entrever, se trata de sugerir, de crear textos que digan algo a quien lee, que tengan la capacidad de tocar: el valor de verdad de la investigación narrativa está en su capacidad de resonar (Pérez de Lara y Contreras, 2010). Esta posibilidad no está en la identificación de la descripción con una realidad externa, sino en la capacidad del relato de mostrar la forma en que se ha creado la relación de diálogo, de pregunta, de exploración. El relato de la experiencia es un texto conversacional (Van Manen, 2003), un juego de singularidades. La escritura es un movimiento de crear sentido; en «esa coincidencia radiante entre experiencia, palabra y pensamiento" (Arnaus, 2010, 153) he ido encontrando los hilos que sostenían la práctica de las educadoras, he descubierto el saber de la experiencia de las educadoras.

Para componer los relatos he ido escuchando, leyendo todo el material de las conversaciones con las educadoras, el material recogido en los diarios de investigación y abriendo con la escritura hasta encontrar una forma de decir, de contar. Ha sido en este ejercicio de lectura y escritura que he aprendido a ver (Welty, 2012) el relato. Los relatos de las educadoras se han conformado a partir de dos partes, una común a los cuatro relatos donde exploraba el proceso a través del cual las educadoras se han ido formando, donde exploraba el proceso de crear y sostener la relación investigadora con cada una de ellas, y donde exploraba el trabajo de pasaje de la experiencia. En la segunda parte de los relatos, se profundiza en la práctica de acompañamiento y en la creación de relaciones educativas en cada una de ellas.

\section{LOS HALLAZGOS: LAS PRÁCTICAS DE RELACIÓN EN LOS RELATOS DE LAS EDUCADORAS}

En el trabajo de relación y en relación con otras y con otros las educadoras van creando un saber pedagógico que las acompaña y las sostiene como pregunta siempre abierta. La relación ha sido origen en su hacerse educadoras, un eje en su proceso -siempre inacabado- de formación. Relaciones significativas con otras educadoras, con maestras y maestros, con mujeres sobre todo. Su proceso de formación va más allá del marco académico y tiene que ver con relaciones en otros espacios de formación no formal, familiares, entre iguales, de compromiso social. En los relatos este proceso de formación se muestra como un tejer relaciones y tejerse en este haz de encuentros. También la relación con la otra o con el otro a quien acompañan en su hacer. Lo que se aprende en la relación es justo eso: la alteridad, la "radical otredad del otro" (Portela, 2008, 171). Una alteridad constitutiva (Levinas, 2002). El saber de la alteridad se funda en la asunción del misterio que siempre entraña la presencia del otro ante mí, un otro irreductible a 
su problemática, a mi diagnóstico. Ni tan siquiera a mi saber. Son educadoras que cuestionan las relaciones de poder frente al otro que lo niegan o que deciden por él, y se preguntan por la honestidad en relaciones que se dicen horizontales pero que representan lo que identifican como relaciones simétricas en las que nos confundimos con el otro, con su dolor. El reconocimiento del otro -de su misterio, de su complejidad- como sujeto con quien conversar, ante quien exponerse, a quien preguntar, se muestra en las prácticas singulares de las educadoras, unas prácticas situadas pues, como dice Pedro Ortega, "no hay lugar para la abstracción" en la relación educativa $(2014,28)$.

Los hallazgos son fruto de las conversaciones con las educadoras, por eso en este texto se hará referencia a fragmentos de las mismas, para poderlos identificar, se usará como referencia el nombre de la conversación que corresponden al nombre ficticio ${ }^{1}$ de la educadora (Núria, Lola, Rebeca y Mayte) y el número de conversación tomando un orden cronológico y en el caso de la conversación grupal se usarán las siglas CG y el número que corresponde.

\subsection{El bicho lo tengo dentro. Aprender a desempañar la mirada}

Es que te sale el bicho, porque el bicho lo tengo dentro. No está fuera. Y pienso que el trabajo es éste: cuando te sacas el bicho de dentro ves las cosas diferentes (Núria 1).

Núria refería con esta imagen una mirada que mira al otro desde el juicio. El ejercicio de limpiar la mirada, de suspender el juicio, es necesario para poder estar en presencia entera en la relación: sacarse el bicho, hacer un trabajo de sí. Núria señalaba el no juzgar como una de las lecciones más importantes en el aprendizaje como educadora. En su trabajo con un grupo de chicas adolescentes, había aprendido a mirar de otra manera, a colocarse en otro lugar: había cosas de cómo se relacionaban estas chicas con sus parejas, entre ellas y con sus cuerpos que le costaban mucho, ahí tenía un trabajo importante con el bicho, por apartarlo de su mirada y poderse colocar en relación, en presencia: sin negar los significados de la otra ni juzgarlos, lo que no quiere decir aceptar todo de la otra y de su forma de relación, buscar ese lugar que no juzga para poder acompañar. Un trabajo necesario para ver algo precioso en la otra o en el otro, para aprender que el otro no es sus circunstancias, su problemática: "Yo tengo la creencia de que por ser un ser humano siempre hay perla», decía Rebeca (Rebeca 2). Una mirada, pues, que confía en el otro y en su posibilidad de ser y de ir más allá, que no se queda en la superficie, una mirada que busca:

1. Para identificar a las educadoras no se ha usado su nombre verdadero por preservar la intimidad de su práctica, del mismo modo que tampoco se hace mención a espacios ni lugares concretos para que los centros y proyectos donde ellas trabajan no se puedan reconocer. Esta decisión responde a un intento de cuidar a las educadoras y a las personas con las que trabajan 
No es fácil, pero en el fondo yo creo que perla siempre hay, la cuestión es que a cada ser humano le han rodeado con tanta porquería que nadie la ve, ni él mismo. La perla como potencia, que hace crecer sus posibilidades. A lo mejor tampoco tiene muchas oportunidades de buscar, de que alguien le reconozca. Si a ti te han tratado bien es más fácil que tú puedas ver tu perla porque alguien te la ha visto, pero si nunca has tenido un trato... chavalines de estos que son tan pequeños y ya tienen situaciones tan complejas, para encontrarle la perla hay mucha porquería por encima (Rebeca 2).

Si el otro es un todo identificable, podemos prevenir el curso de acción; si el otro es un problema, lo veremos como un problema. Sin embargo, si el otro es algo inapresable, un ser humano que vive una situación de complejidad, la forma de colocarnos será también compleja, una forma de la que nunca estaremos seguras. La creación de conceptos sobre el otro no deja de ser una fantasía que elaboramos sobre el otro, corremos el peligro, decía Rebeca, de crear una imagen del otro sin el otro (Rebeca 1). Pensarse en relación es, por tanto, un trabajo de mirar al otro que está en mí, ponerme en primera persona, pero sin poner el horizonte en mí -no soy la medida de todo-. El bicho aparece en forma de aspiración omnipotente, nos hace creer que cambiaremos a la otra o al otro, que asumirá nuestros significados, cuando lo que podemos hacer en el acompañamiento es mostrar otros significados, "ayudar a aclararse». La tentación de cambiar al otro es muy grande, por eso hay que mantener activo el trabajo del bicho, porque, como dice Núria, «el bicho vuelve cuando menos te lo esperas» (Núria 2).

\subsection{Una disposición del cuerpo. La escucha y la atención en la relación educativa}

La escucha de la otra persona es lo que pone en funcionamiento, la escucha es lo que pone en marcha, y que la otra persona trae cosas más interesantes que las tuyas. La escucha es un filón para que el mundo... la escucha amorosa, la escucha del cuidado, del puedo ser capaz de emocionarme con lo que tú me dices. Esa disposición del espíritu, supongo, o del cuerpo, del cuerpo (Mayte 1).

En las primeras conversaciones con Mayte, para explicar cosas de su práctica como educadora, recurría a menudo a su relación con el teatro, que había sido una fuente de sentido importante, le había permitido, entre otras cosas, aprender la importancia de la escucha: "Si no hay escucha no hay teatro" (Mayte 1), es lo que hace funcionar la relación. Si no hay escucha no hay relación. Una escucha que tiene que ver con la disposición, con la acogida que hacemos de lo que la otra o el otro trae, una escucha del gesto. Mayte lo llama "escucha amorosa»: "Esa escucha tiene que ver con lo que yo llamo poner antenas» (Mayte 2). La escucha amorosa que cuida al otro, atender a lo que pasa, estar ahí en la medida en que -y donde- la otra nos reclama, asumir una responsabilidad con la otra o el otro. Es saber colocarnos en relación, en sintonía:

Dando teatro con los más peques, en este caso eran cinco años, si yo estaba atenta y con las antenas ahí, con la atención bien a punto, yo era capaz de sacar a la luz 
ciertos ingredientes y que aquello creciera mucho más, mucho más de lo que estaban dando. Pero, claro, si, en ocasiones en determinados contextos, no eres capaz de hacer eso es mejor que te calles, porque con poco que vas a hacer vas a romperlo (Mayte 3).

Mayte señalaba la dificultad que encontraba para trabajar con niños y niñas pequeños, por la enorme libertad que vive desplegada en estos espacios, para no romper el ritmo que crean, para no distorsionar: los ingredientes que hacen crecer una situación están allá, no hace falta que la educadora los ponga, en todo caso los hace más visibles. La escucha atenta pasa por no poner por delante lo que nosotras llevamos, por preguntar qué necesitas. A veces, la otra o el otro no está en disposición de responder, o responde de una forma que nos obliga a escuchar de nuevo, a estar atentas. Arriesgamos con aquello que creemos que nos pide la otra, seguimos una intuición, nos hacemos cargo de lo que está pasando, pero sin pasar por encima de la otra ni ocupar su lugar, una frontera sutil, tenue, fácil de traspasar incluso con las mejores intenciones.

Para que haya escucha necesitamos un silencio en nosotras -para escuchar la palabra (o el gesto) de la otra- que posibilite el nacimiento de la palabra. En ocasiones, en el hacer de las educadoras hay demasiado ruido, palabra o discurso, demasiada actividad que no deja tiempo para escucharse. Mayte hablaba del ritmo acelerado que a menudo nos supera, un "potro desbocado": "Yo creo que el silencio siempre posibilita, da la posibilidad. Porque es una manera de parar. Hay que parar» (Mayte 2). En relación a este tiempo detenido, un espacio vacío, Núria relataba una escena donde se podía leer la distorsión, la dificultad que tenemos para parar. La propuesta de la entidad donde trabajaba, como equipo, era aprender a ir dejándose llevar poco a poco; las educadoras y los educadores más experimentados hacían de referentes para aquellas que se iniciaban, había un soporte, un apoyo, la presencia de alguien allá acompañando:

Lo que me pasaba es que empezaba a trabajar con una monitora muy joven, que era el primer año que trabajaba en la ludoteca y había momentos que igual se quedaba un poco bloqueada, que no sabía qué hacer y yo llegaba como Súper Núria y lo quería hacer todo. Porque claro, yo con mi problema personal no podía soportar aquel silencio. Llegó un día que, al acabar, cuando se fueron los niños le dije: te tengo que pedir disculpas porque soy una agonías y eso no está bien. No es bueno ni para ti, ni para mí, ni para los niños. Si hay algún momento que nos desconcierta nos quedamos en el vacío y a ver qué hacemos (Núria 3).

Para que quien está aprendiendo a ser educadora pueda alimentar la intuición necesita a alguien que la acompañe, no que le resuelva, cuesta dejar espacio, quedarse en el vacío y pensar qué se hace, y no correr a llenarlo de actividad, despojarnos del activismo y exponernos al no saber, a la espera, al vacío, porque un espacio solo puede florecer cuando no está saturado.

Mayte habla de escuchar desde el cuerpo, una escucha en que la palabra del otro «te vibra», una disposición del espíritu, decía ella, que va más allá de la 
escucha racional, que requiere una gran consciencia de sí. Una escucha del cuerpo: "La escucha creo que te cierra como la posibilidad de ocupar al otro, el teatro eso lo hace muy bien porque la escucha un poco del aquí y ahora, aquí y ahora, qué pasa, qué está pasando y en eso te sitúa el teatro. Y es que eso: si tú escuchas no ocupas al otro o a la otra” (Mayte 3).

La escucha, entonces, es un viaje hacia el otro, pero sin salir de ti, de los límites del cuerpo, porque a menudo tendemos a fundirnos, a desplazarnos al lugar de la otra en un ejercicio de solapamiento donde no hay presencias sino una única presencia que todo lo ocupa, donde no hay acompañamiento posible. Las relaciones, decía Mayte, «tienen que ver con los cuerpos», el cuerpo en disposición a acoger al otro, pero también como portador de presencia.

\subsection{Descálzate porque es terreno sagrado. La autoridad y el reconocimiento en la relación de alteridad}

Depende del concepto que tú tengas, claro, si para ti un niño es un ser superimportante que se está formando, si la formación de un ser humano es más importante que otra cosa, tu forma de relacionarte con eso es muy diferente. Lo que siento es que hay veces que la gente entra como «a saco», y dices: ¡eh! Que aquí hay algo: descálzate porque es terreno sagrado (Rebeca, CG 4).

Estar descalza recoge algo de la inmensidad que se abre en la relación, la intensidad que es inagotable, que es incontrolable; hay algo importante que se juega en la relación, por eso hay que descalzarse, para recordar lo delicado e incierto de lo que hacemos, para no pasar como si nada, o pasar violentando, o pasar desacralizando la relación. Rebeca trabajaba como profesora en un programa de transición laboral, es muy poco el tiempo que está con las chicas, apenas un curso, pero sabe que necesita hacer un trabajo de relación para que se dejen tocar por lo que les pasa, ellas y ella, para -en una determinada relación institucionaldejarse tocar por la singularidad de cada una: "Tú puedes seguir echando lluvia que si la otra tiene el chubasquero puesto no pasa nada, entonces: ¿cómo sacar el chubasquero de la gente para que pueda caer la lluvia?» (Rebeca 2). Quitarse el chubasquero es exponerse, algo que nunca es inocuo; si la dejamos caer, la lluvia mojará. Dejarse tocar por la relación da miedo, podemos ver cosas de nosotras que no nos gustan. Y padecer. Para que pueda haber relación hay que quitarse el impermeable, un proceso, contaba Rebeca, que pasa por crear gestos simbólicos que van desplazando la relación de los lugares para poderla crear desde sí: "Porque si no te pones como persona te pones como lugar y si te pones como lugar te pones como poder coercitivo hacia el otro".

Para Lola este desplazamiento tiene que ver con asumir una responsabilidad con la otra o el otro en la relación. Tiene que ver con la "autenticidad" en el ser educadora, con no ofrecer en falso, con sostener aquello que dices y llevas a la relación. Los chicos y las chicas con las que trabajan educadoras y educadores 
sociales saben quién es auténtico y quién no: "Nosotras nos comemos la cabeza con la relación y ellos te calan a la primera» (Lola 3):

Es fuerte, pero me he encontrado con que muchas veces la relación necesita como una prueba, si tú estás segura de lo que haces, lo sabes y te mantienes y lo explicas. Quizás no lo puedes asumir, pero también lo puedes explicar, decir: mira, yo veo esto, a lo mejor tú necesitas eso, yo no te lo puedo ofrecer, yo puedo ofrecer esto. Si tú estás segura de lo que haces, te mantienes, las cosas avanzan. Si no, si te excusas en la institución, en la distancia, entonces las cosas no avanzan porque no es eso lo que se está moviendo (Lola 3).

El sentido no lo encontramos en la institución sino en el otro y en la relación con él. Una educadora "auténtica» se expone, se pone en juego sin escudarse o diluirse en la norma o en la institución. Si lo que media no es el encuentro, la relación no va, no se mueve. Las educadoras y los educadores tienen la responsabilidad de situarse y situar al otro en lo que pueden sostener, asumir lo que pueden hacer sin caer en la omnipotencia ni esconderse. Cuando conocí a Núria, era su último año como educadora en la entidad donde trabajaba. Así que estaba cerrando y ocupándose del traspaso, como ella decía. Era un momento delicado e importante, llevaba mucho tiempo trabajando allá y era un lugar significativo en el que se había dedicado mucho a cultivar la relación: con las chicas, con las mujeres, con los niños y niñas... El traspaso, sin embargo, era un traspasar tareas y funciones, la relación es imposible de traspasar, a pesar de que otra educadora llegaría y se encargaría de acompañar a las personas que Núria acompañaba:

Estábamos en la reunión de traspaso y me decían:

-Y esto como lo haremos si tú no estás, como hablaremos con...

-Bueno, pues de otra manera, desde otra relación. No puedo traspasar la relación tal cual, la otra no lo entendería. Estaría totalmente fuera de lugar. Tú tienes una relación con ella y ya irá creciendo, seguramente hacia un lugar diferente de donde ha crecido la mía (Núria 2).

En ese estar presente de verdad y de una forma responsable reside la posibilidad de que circule el reconocimiento, de que la otra o el otro te autorice a acompañarla o acompañarlo en momentos significativos, delicados, frágiles, importantes de sus vidas. Eso pasa por que «el otro te dé permiso para entrar, te da permiso para que de verdad entres y le ayudes» (Núria CG 4). A veces ese permiso no está, y entonces la relación no es posible. Mayte me explicaba las dificultades que había tenido en un curso para trabajar con las madres de los niños con los que trabajaba en la asociación en la que estaba contratada en ese momento: no había encontrado la manera de conectar con ellas, de establecer un vínculo de confianza. Era un grupo de madres extranjeras con las que el idioma era una primera barrera. María recurría a un traductor, pero esa dificultad de comunicación afectaba a la relación. Tenía que evaluar un programa con ellas, pasarles un cuestionario. Se preguntaba si era ella la que transmitía la desconfianza que percibía en aquellas madres. El 
espacio - un despacho- era otra barrera. Los despachos, decía, tienen una disposición que no facilita el encuentro; iba inventando formas de disponer el mobiliario, lugares donde colocarse para iniciar el contacto. Pero creía que había algo más que el idioma o el espacio, algo que tocaba directamente la relación. Quizás se trataba del permiso, del reconocimiento, algo que no se puede resolver en un tiempo breve, que requiere un recorrido. La aparente resistencia de estas mujeres podía tener que ver, también, con una desconfianza en la institución, ya que Mayte se encargaba de tramitar las ayudas económicas y eso podía estar interfiriendo en la relación. Sin embargo, Mayte se preguntaba por lo que ella creaba o generaba o no ponía para que la relación no surgiera:

También pueden no querer. A lo mejor no desean participar de esta propuesta. Yo no me veo forzando, para mí no tiene ningún sentido. Es como querer abrir las aguas y eso en absoluto (Mayte 4).

\section{UNA PEDAGOGía DE LA ALTERIDAD EN (Y DESDE) LA EXPERIENCIA DE LAS EDUCADORAS}

Porque para pensar la experiencia necesitamos mantenernos cerca de ella, la indagación narrativa toma como punto de partida y lugar de llegada la experiencia vivida (Clandinin y Rossiek, 2007, 55). Su propósito no es explorar la experiencia vivida para ver más allá, sino permanecer en ella para ver qué la sostiene. Pensar con las historias (Bochner, 2001). La pregunta de investigación se dirige entonces a la práctica de las educadoras para explorar qué la sostiene como saber. Un saber fundado en la relación de alteridad. Lo que la sostiene son hallazgos que funcionan como hilos -entretejidos- de sentido:

\footnotetext{
Encontrar el hilo -o los hilos- de sentido, intentar visualizarlos en sus recorridos, ver cómo atraviesan la experiencia, cómo la recorren por completo, pero con un sentido propio, es la tarea propia de la significación en el proceso de investigación, del despertar del pensamiento pedagógico que ella nos trae. Y más allá de ello, podremos ver si hacen trama con otros hilos, si construyen un tejido con otras experiencias, pensamientos y saberes que nos permitan ir más allá, abriendo nuevos horizontes de sentido (Contreras y Pérez de Lara, 2010, 79).
}

Los hilos también me han permitido poner en diálogo lo que emergía de la exploración de la experiencia de las educadoras con el trabajo de otras autoras y autores que he ido revisitando durante el proceso, textos que ayuden a ver (Praetorius, 2002). En esta relación no hay un antes y un después, se trata más bien de una lógica circular que pone en juego palabra y experiencia, de dar forma a una relación conversacional (Van Manen, 2003, 127) que permite mostrar la complejidad de la pedagogía y atravesarla. 


\subsection{La experiencia del tú}

Tal vez allí resida toda posibilidad y toda intensidad del cambio de amorosidad en las relaciones pedagógicas: nunca ser impunes cuando hablamos del otro; nunca ser inmunes cuando el otro nos habla (Skliar, 2009, 147).

Mireille Cifali (2005) señala que, en tanto portadoras y portadores de nuestra práctica, somos responsables de la acción, lo que nos lleva a comprender que no es el otro quien debe cambiar. La relación educativa no consiste tanto en hacer cosas en el otro; se trata, sobre todo, de hacer algo en nosotras, de producir desplazamientos en nosotras. La irreductibilidad del otro hace posible la relación educativa, lo que supone asumir que jamás podré conocer del todo al otro, que la otra no es algo que yo tenga que comprender en su totalidad: "Cuando se comprende al otro y se pretende conocerlo se le sustrae en realidad toda legitimación a sus pretensiones [...] La pretensión de conocer al otro anticipándole cumple la función de mantener en realidad a distancia la pretensión del otro" (Gadamer, 1977, 436).

Pretender este conocimiento totalizador del otro es colocarse en un lugar de poder respecto de él o ella, negándole. Luce Irigaray en su texto Ser dos (1997) apela a acoger al otro como misterio para respetar y salvaguardar su alteridad, para no dominarlo, ni hacerlo mío, ni someterlo a mi ley. Un pensamiento sensible que ilumina formas de estar con el otro. Un misterio que deviene medida en la relación. Como decía Rebeca, asumir al otro, antes que como diagnóstico, como problema, como cliente, como un ser humano con su complejidad (CG 1), sin categorizarlo ni tematizarlo. Cómo pienso a la otra o al otro tiene que ver conmigo, dónde me refugio, como se pregunta Caterina Lloret (2009), dónde estoy yo cuando hago de ti objeto de mi mirada, cuando te describo, cuando te clasifico. Si dejo de ser inmune al otro, me expongo. Lo que nos pasa en la relación de alteridad es la experiencia del tú, una relación en que la presencia del otro hace algo en mí. La experiencia del tú, dice Gadamer (1977), es experimentar al otro como un tú, dejarse hablar por el otro. Esos desplazamientos de los que habla Mireille Cifali, esos movimientos de apertura a la relación es lo que he explorado como saber de la alteridad en la experiencia de las educadoras. El sujeto, dice Gómez Ramos (2015), es sujeto por la existencia del tú, por la aparición de un tú que le interpela. Saber al otro, saberlo como presencia siempre inapresable, siempre incomprensible (Levinas, 2002) que me dispone, que coloca en el centro de la relación el cuidado del otro, un cuidado del otro que vuelve a mí como un cuidado de sí (Gómez, 2015), desplazando la ontología (Llevadot, 2011) y colocando la pregunta por el otro en el centro de la relación.

\subsection{Ver desde otro lugar, un saber fundado en la mirada}

Para poder estar en relación hay que hacer un trabajo de mirada, una mirada limpia, desempañada, una mirada que ha apartado del sí el bicho -que reduce al 
otro y lo niega como ser humano complejo e inaccesible, como misterio- del que hablaba Núria. El bicho nos hace saltar el trabajo de mediación, el trabajo que permite ponernos en relación con el otro y dejarnos decir por él: «El otro es una imagen, pero sobre todo el otro es quien rompe cualquier imagen» (Mèlich, 2015, 58). Hay que hacer un trabajo con ese bicho que empaña la mirada, hay que apartarlo para poder ver algo "precioso en el otro", ese "ver cosas en el otro" del que habla Fátima Portela (2008, 169).

Núria Pérez de Lara (2008) recupera los versos de Pessoa: "Vale más la pena ver por primera vez una cosa que conocerla / porque conocer es como no haber visto nunca por primera vez». Ver por primera vez, una mirada capaz de asombrarse ante la otra y el otro como decía Lola, un asombro del que puede brotar el pensamiento (Zambrano, 2011). La mirada que espera, que no corre a conocer al otro, que contempla al otro en su inmensidad, en su indefinibilidad. Ver por primera vez es abrir en nosotras una pregunta por el otro que siempre queda abierta, que hacemos cada vez que entramos en relación, que nos hace descalzarnos ante el otro: "Una mirada que partiera de esa humildad que permite el vacío que acoja la palabra y el ser del otro, la otra, sin pretender interpretarla desde nuestro saber» (Pérez de Lara, 2013, 6). Una mirada capaz de poner en suspenso, que se hace más difícil en el trabajo de las educadoras, de tiempos breves y situaciones complicadas y dolorosas. No se trata de abandonar determinadas estrategias que te ayudan a sostenerte en el trabajo, sino de tomarse el tiempo necesario para observar y escuchar, sin anticipar. Poner en suspenso, esta es la condición de una relación educativa fructífera: la capacidad de hacer vacío, de abandonar aquello que crees saber, deshacerse del saber acumulado para ir al encuentro del otro (Manenti, 2002).

Y ser capaz de confiar en la otra, y en la relación. Una mirada que confía en la perla de la que hablaba Rebeca. La mirada de la alteridad es una mirada amorosa. Amar no significa aceptar todo del otro, amar es un juego de distancias y de límites delicado, es un arte finísimo, un equilibrio entre amor y apropiación, entre estima y compasión. Una mirada amorosa no es aquella que se funde en la otra, ni que se niega como otra en la relación. Es una mirada que cuida al otro o a la otra, pero sin apropiarse. Luce Irigaray (1994) habla de una mirada contemplativa que observa pero que no somete, que mira sabiéndose otra y sabiendo al otro otro que no puede dominar, ni tan siquiera conocer, que mira atentamente para dejarse decir por la presencia de la otra.

\subsection{Una escucha capaz de silencio, estar atentas al otro, estar atentas a la relación}

La escucha atenta de la que hablaba Mayte es una disposición del cuerpo. Necesita del silencio. Hacer vacío para poder escuchar a la otra, acallar el ruido que no me deja ver y atender a quien tengo delante, "palabras que actúan como ruido, como distorsión sonora que llenan el espacio, que impiden el silencio necesario de la escucha atenta" (Contreras, 2009, 8). Hay que parar, esperar, no correr a interpretar las palabras del otro, no proyectar. Es un ejercicio de atención a lo que es, 
a lo que deviene. La atención es una disposición del cuerpo y necesita de silencio. Rebeca hablaba de la sencillez necesaria para descentrarse de sí, para poder estar en presencia entera, atenta a la otra y a la relación. Si el espacio está lleno de la educadora no hay lugar para la relación.

Parar para poder estar en esta disposición de acogida, suspender la inercia de la acción. Ser capaz de suspender la intención para abrirse a la atención, dirá Maaschelein (2006). Dice Simone Weil $(2001,153)$ que «la atención se halla ligada al deseo", y aclara: "no a la voluntad, sino al deseo, o más exactamente, al consentimiento». La atención nace del deseo de estar en relación, no puede entonces ser fruto de la intención o la voluntad de hacer algo en el otro, de esta tentación tan grande de cambiar al otro de la que Núria hablaba. Que la atención venga de la mano del deseo nos coloca en una posición de pasividad respecto al otro, de su palabra y de su gesto. En un tiempo de espera paciente que está atenta hasta que brota la luz (ibíd.: 156), hasta dejarse decir por quien está delante de mí (Portela, 2008). Es el gesto de descentrarse del que hablaba Rebeca, la disposición del cuerpo de la que hablaba Mayte, una disposición para acoger al otro, estar atenta y cuidar la distancia que hay entre nosotras y el otro, la distancia que une a la vez que separa (Portela, 2008), allá donde es posible que nazca algo entre nosotras.

Simone Weil $(2001,154)$ habla de este acto de atención -un acto creadorcomo una acción inactiva, una capacidad de permanecer pasiva ante aquello que deviene, ante la otra, ante la relación. La creación nace de la luz que brota, porque hay una espera que la hace posible. Y quizás, en el hacer de las educadoras la creación es la capacidad de responder al otro, de hacerse cargo de la responsabilidad como educadoras, de hacer algún movimiento que requiere esta responsabilidad. De responder al otro, una respuesta fruto de la espera, del tiempo de silencio. Si no media un tiempo, un silencio, hay reacción en vez de respuesta, vorágine de actividad:

Hay que sostenerse en ese vacío de la mente con un corazón firme. Y entonces, sólo entonces, es cuando aflora la respuesta; una respuesta todavía más precisa de la que creíamos tener. Entre la pregunta y la respuesta debe existir, de mediar, un vacío, una detención de la mente, una cierta suspensión del tiempo. Por varias razones, mas ante todo por ésta que ahora señalamos: que el corazón debe de asistir, en todos los sentidos de la palabra, al acto de responder ante algo. Porque responder es responder ante algo, presentarse ante algo. Y sin la asistencia del corazón la persona nunca está del todo presente (Zambrano, 2011, 150).

\subsection{El arte de pedir permiso. Reconocimiento y autoridad en la relación}

Núria decía que como educadoras estamos allá disponibles, pero que es la otra o el otro quien elige el vínculo, su forma de estar y sostener este vínculo, la otra nos tiene que autorizar para entrar en relación, sin este permiso somos como intrusas en las vidas de los otros. Para que el otro nos autorice hace falta un tiempo de relación, porque nos tiene que reconocer. El permiso es un gesto 
complejo, sutil, que hay que estar atenta para percibir, pero necesario para poder estar de verdad en la relación:

Necesité aprender a vivir el tiempo de la relación, un tiempo muchas veces más lento, aunque, a veces, da un salto en un instante; un tiempo complejo, un tiempo que vaya al ritmo de la vida, a ritmo de las relaciones. Un tiempo que es también continuo entre presencia y ausencia del día a día y nos permite conocer el hilo de la vida que cada una va viviendo, y así, ir viendo si podemos enlazar el propio hilo con otros. Algunas veces podemos, otras no, en algunos hacemos un lazo, en otros nos hacemos un lío... sea como sea, necesitamos un tiempo tranquilo que se deje mecer por el sentido de la vida cotidiana. Tiempo que permite mirar a la otra, mirarse una misma y mirar la relación que vivimos (Caramés, 2008, 103).

El reconocimiento no se puede forzar (Van Manen, 2007), no se puede precipitar la relación, hace falta esperar que la otra o el otro te dé el permiso. Cuando no está el permiso tenemos esa sensación de violencia de la que hablaba Mayte, esa vivencia de intromisión. ¿Qué hacer entonces cuando no está el permiso?, ¿qué hacer para pedirlo? Rebeca hablaba de ponerse en la relación como persona y no como lugar -de poder, como educadora-, sino desde sí. Van Manen (2003) habla de la autoridad como algo que solo es posible desde el amor, el afecto y la autorización, no desde el poder. Para eso hay que salir del lugar que la institución marca, del lugar construido desde el afuera del sujeto que lo ocupa, hay que darle sentido, colocarse en relación desde sí:

Pensar desde nuestros sitios impone una realidad, la realidad de lo que hay; salir de nuestros sitios para pensar otra realidad, aún no impuesta, aún no habida, propone una maravilla: "la maravilla de salir con el otro», por ejemplo. Pero, quizás también propone alguna infracción, alguna obstinación, alguna elección radical en mi existir (Pérez de Lara, 1997, 171).

El saber de la alteridad es un saber que te sostiene sin resolver jamás el encuentro, un saber que hace de plataforma para salir del lugar e ir a la búsqueda del otro, a su encuentro. Porque más que una búsqueda, el otro es un encuentro. Un hallazgo siempre inesperado que provoca en mí desplazamiento, extrañamiento, transformación.

\section{REFERENCIAS BIBLIOGRÁFICAS}

ARnaus, R. (2005) La mediació en educación. Duoda Revista d'Estudis Feministes, n. ${ }^{\circ}$ 29, 101-107.

ARnaus, R. (2010) El sentido libre de la diferencia sexual en la investigación educativa, en CONTRERAS, J. y PÉREZ DE LARA, N. (comps.) Investigar la experiencia educativa. Madrid, Morata, 153-174.

Benjamin, W. (1998) El narrador. Para una crítica de la violencia y otros ensayos. Madrid, Taurus.

BOCHNER, A. P. (2001) Narrative's Virtues. Qualitative Inquiry, vol. vII, n. ${ }^{\circ}$ 2, 131-157. 
CARAmÉs BoAda, M. (2008) La trena de llibertat, temps i amor enfilant les preguntes per la relació educativa. Duoda Estudis de la Diferència Sexual, n. ${ }^{\circ}$ 35, 99-117.

Cifali, M. (2005) Enfoque clínico, formación y escritura, en Paquay, L.; Altet, M.; Charlier, É. y Perrenoud, P. (coords.) La formación profesional del maestro. Estrategias y competencias. México, Fondo de Cultura Económica, 170-196.

Clandinin, J. (2013) Engaging in narrative Inquiry. Walnut Creek, Cal., Left Coast Press.

Clandinin, J. y CONNELly, F. M. (2000) Narrative Inquiry. Experience and Story in Qualitative Research. San Francisco, Jossey-Bass.

Clandinin, J. y Rossiek, J. (2007) Mapping a Landscape of Narrative Inquiry». Borderland Spaces and Tensions, en Clandinin, J. (ed.) Handbook of Narrative Inquiry. Mapping a Methodology. California, Sage, 35-75.

Conle, C. (1999) Why narrative? Which narrative? Struggling with Time and Place in Life and Research. Curriculum Inquiry, vol. 29, n. ${ }^{\circ}$ I, 7-32.

Conle, C. (2000) Thesis as Narrative or "What Is the Inquiry in Narrative Inquiry? Curriculum Inquiry, vol. 30, n. ${ }^{\circ}$ II, 189-214.

Connelly, F. M. y Clandinin, J. (1995) Relatos de Experiencia e Investigación Narrativa, en LARrosa, J. et al. Déjame que te cuente. Ensayos sobre narrativa y educación. Barcelona, Laertes, 11-59.

Contreras Domingo, J. (2009) Prólogo, en Skliar, C. y Larrosa, J. (comps.) Experiencia y alteridad en educación. Rosario, Homo Sapiens Ediciones, 7-11.

Contreras Domingo, J. y Pérez de Lara Ferré, N. (2010) La experiencia y la investigación educativa, en CONTRERAS, J. y PÉREZ De LARA, N. (comps.) Investigar la experiencia educativa. Madrid, Morata, 21-86.

Contreras, J. y Orozco, S. (2016) Explorando el saber pedagógico en nuestras clases, en CONTRERAS, J. (comp.) Tensiones fructíferas: explorando el saber pedagógico en la formación del profesorado. Barcelona, Octaedro, 11-31.

Gadamer, H.-G. (1977) Verdad y método I. Salamanca, Ediciones Sígueme.

GADAMER, H.-G. (1992) Verdad y método II. Salamanca, Ediciones Sígueme.

Gómez Ramos, A. (2015) Sí mismo como nadie. Madrid, Libros de la Catarata.

Irigaray, L. (1994) Amo a ti. Bosquejo de una felicidad en la historia. Barcelona, Icaria.

IrIgARAY, L. (1997) Ser dos. Barcelona, Paidós.

Larrosa, J. (2003) Entre las lenguas. Lenguaje y educación después de Babel. Barcelona, Laertes.

LARrosa, J. (2008) Una lengua para la conversación, en MAAschelein, J. y Simons, M. (eds.) Mensajes e-ducativos desde tierra de nadie. Barcelona, Laertes, 45-56.

LARrosa, J. (2009) Experiencia y alteridad en educación, en SkLiar, C. y Larrosa, J. (comps.) Experiencia y alteridad en educación. Rosario, Homo Sapiens Ediciones, 13-44.

LÉVINAS, E. (2002) Totalidad e infinito. Ensayo sobre la exterioridad. Salamanca, Ed. Sígueme.

Llevadot, L. (2011) Tú. Aprender a no saber, en CRUZ, M. (ed.) Las personas del verbo (filosófico). Barcelona, Herder, 31-70.

Lloret Carbó, C. (2009) Nos-otros, en lloret Carbó, C. Mestra de mestres. Barcelona, Publicacions de la Universitat de Barcelona y Departament de Didàctica i Organització Educativa de la Universitat de Barcelona.

Manenti, E. (2002) La Casa del Po, en Diotima El perfume de la maestra. En los laboratorios de la vida cotidiana. Barcelona, Icaria, 162-175.

Masschelein, J. (2008) Pongámonos en marcha, en MaAschelein, J. y Simons, M. (eds.) Mensajes e-ducativos desde tierra de nadie. Barcelona, Laertes, 21-30. 
Maturana, H. (1997) La realidad ¿objetiva o construida? I. Fundamentos biológicos de la realidad. Barcelona, Anthropos.

MÈLICH, J.-C. (2002) Filosofía de la finitud. Barcelona, Herder.

MÈLICH, J.-C. (2015) La lectura com a pregària. Barcelona, Fragmenta editorial.

Mortari, L. (2002) Tras las huellas de un saber, en Diotima El perfume de la maestra. En los laboratorios de la vida cotidiana. Barcelona, Icaria, 153-162.

Ortega, P. y otros (2014) Educar en la alteridad. Murcia, Redipe y Editum Universidad de Murcia.

PÉREZ DE LARA, N. (1997) Imágenes del otro. Imágenes, tal vez, de una función pedagógica otra, en larrosa, J. y Pérez de lara, N. (comps.) Imágenes del otro. Barcelona, Virus Editorial, 163-173.

PÉRez de LARA, N. (2008) A propósito de la diversidad. Kikiriki Cooperación Educativa, n. ${ }^{\circ}$ 89, 22-29.

Pérez de Lara, N. (2009) Escuchar al Otro dentro de sí, en Skliar, C. y Larrosa, J. (comps.) Experiencia y alteridad en educación. Rosario, Homo Sapiens Ediciones, 45-77.

PÉREZ DE LARA, N. (2013) Entre el amor a la docencia y el deseo de saber: experiencia e investigación. Bogotá, Babel Libros.

PIUssi, A. M. (2007) Del saber de la experiencia al saber de la práctica, en SofíAs Saber es un placer. La práctica política de mujeres que buscan dar sentido libre a la educación. Madrid, Horas y Horas, 66-67.

Portela, F. (2008) Atención y amor en educación. El juego de las distancias. Duoda estudis de la Diferència Sexual, n. ${ }^{\circ} 35,169-174$.

Praetorius, I. (2002) La filosofía del saber estar ahí. Para una política de lo simbólico. Duoda Revista d'Estudis Feministes, n. ${ }^{\circ} 23,99-110$.

Rivera Garretas, M. (2011) Ella es demasiado libre. La revolución del tiempo y del amor. Duoda Estudis de la diferencia sexual, n. ${ }^{\circ} 41,46-64$.

Rivera Garretas, M. (2012) El Amor es el Signo. Educar como educan las madres. Madrid, Sabina editorial.

SkLiar, C. (2009) Fragmentos de experiencia y alteridad, en SkLIAR, C. y LARROSA, J. (comps.) Experiencia y alteridad en educación. Rosario, Homo Sapiens Ediciones, 143-160.

TARDIF, M. (2004) Los saberes del docente y su desarrollo profesional. Madrid, Narcea.

VAn Manen, M. (2003) Investigación educativa y experiencia vivida. Barcelona, Idea Books.

VAN MANEN, M. (2007) El tacto en la enseñanza. El significado de la sensibilidad pedagógica. Barcelona, Paidós.

WeIL, S. (2001) La gravedad y la gracia. Madrid, Trotta.

Welty, E. (2012) La palabra heredada. Salamanca, Impedimenta.

ZAMBONI, C. (2002) Intermedio: inventar, agradecer: pensar, en Diotima El perfume de la maestra. En los laboratorios de la vida cotidiana. Barcelona, Icaria, 22-28.

Zambrano, M. (2011) Notas de un método. Madrid, Tecnos. 
